\title{
Community gardening in disadvantaged neighborhoods in Phoenix, Arizona: Aligning programs with perceptions
}

\author{
Tommy Bleasdale, ${ }^{a}$ School of Human Evolution and Social Change, Arizona State University

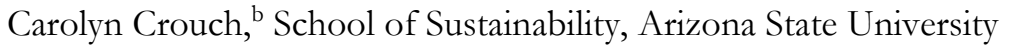 \\ Sharon L. Harlan, ${ }^{\mathrm{c}}$ School of Human Evolution and Social Change, Arizona State University
}

Submitted 29 July 2010 / Accepted 26 April 2011 / Published online 16 May 2011

Citation: Bleasdale, T., Crouch, C., \& Harlan, S. L. (2011). Community gardening in disadvantaged neighborhoods in Phoenix, Arizona: Aligning programs with perceptions. Journal of Agriculture, Food Systems, and Community Development, 1(3), 99-114. http://dx.doi.org/10.5304/jafscd.2011.013.007

Copyright (C) 2011 by New Leaf Associates, Inc.

\begin{abstract}
This study examined a struggling community gardening program in a low-income minority community in Phoenix, Arizona. The gardening program exists within a larger local food initiative organized by a nonprofit community development organization. The nonprofit's goals for the community gardening program are to provide residents with opportunities for education, extra income and socializing. In partnership with the nonprofit and

\footnotetext{
${ }^{a}$ Corresponding author: $\mathrm{PhD}$ student in the Environmental Social Sciences Program, School of Human Evolution and Social Change, Arizona State University, P.O. Box 872402, Tempe, AZ 85287-2402 USA; tbleasda@asu.edu; +1 (480) $747-2280$

${ }^{\mathrm{b}}$ Master of Arts in Sustainability, School of Sustainability, Arizona State University; carolyn.crouch@asu.edu

${ }^{\mathrm{c}}$ Associate Professor, School of Human Evolution and Social Change, Arizona State University, P.O. Box 872402, Tempe, AZ 85287-2402 USA; sharon.harlan@asu.edu
}

local residents, we undertook a study to determine the potential for increasing the recruitment and retention of local gardeners in order to sustain a successful community gardening program. We used interviews and participant observation to create an exploratory survey that measured residents' perceptions of benefits and burdens associated with gardening. Results revealed that while respondents had a level of gardening interest and experience in the community, they also lacked awareness about the gardening program. Perceptions of the benefits and burdens of gardening varied among current gardeners, ex-gardeners, and people who had never gardened. The benefits of gardening suggested by many residents differed from the local food initiative goals. If community gardens and local food initiatives are to succeed, organizers should align their programs with the desires of neighborhood residents and educate them about a wide range of potential benefits of gardening to both individuals and neighborhoods. 


\section{Keywords}

community garden, community food initiative, quality of life plan, urban agriculture, food justice, community partnership, food desert

\section{Introduction}

It is well established that there are disparities in access to supermarkets between lower- and higherincome communities in the United States (Alwitt \& Donley, 1997; Baker, Schootman, \& Barnidge, 2006; Block \& Kouba, 2006; Morland, Wing, \& Diez Roux, 2002). Many low-income minority residents who live in areas commonly known as food deserts struggle to reach a grocery store, spending significantly more time (19.5 minutes) traveling to a grocery store than the national 15 minutes average (USDA, 2009). The burdens of travel distance, time spent in transit, and the high price of food weigh heavily on vulnerable populations. According to the United States Department of Agriculture, "low-income households must allocate a higher share of both their income and time budgets to food if they wish to consume palatable, nutritious meals" (Golan, Stewart, Kuchler, \& Dong, 2008).

An unjust disparity in access to and affordability of quality foods highlights the greater social and environmental health burdens experienced in lowincome areas of the United States (Algert, Agrawal, $\&$ Lewis, 2006). Easy access to convenience stores and fast food outlets increases residents' exposure to unhealthy food, and the potentially negative effects of such a diet may disproportionately affect the health and well being of low-income communities and minority populations (Larson, Story, \& Nelson, 2009; Pearce, Blakely, Witten, \& Bartie, 2007).

Community food initiatives endeavor to alleviate some of these burdens. Community gardens in particular provide a way to connect the urban poor with inexpensive fruits and vegetables (Gottlieb \& Fisher, 1996). Placed in the context of poor minority neighborhoods, community gardens are enmeshed in a network of justice issues. Food justice is a framework with theoretical links to both environmental and social justice (Wekerle, 2004).
"Food justice places the need for food security access to healthy, affordable, culturally appropriate food - in the contexts of institutional racism, racial formation, and racialized geographies" (Alkon \& Norgaard, 2009, p. 289). In blighted urban neighborhoods, community gardens provide environmental benefits in the form of green space (Gottlieb \& Fisher, 1996) and a social gathering place where vulnerable populations can empower themselves through democratic organization (Armstrong, 2000; Levkoe, 2006). Community gardens are places where both social and environmental justice can be framed and practiced (Irazábal \& Punja, 2009).

In this article we focus on the potential of a locally organized food initiative to revitalize a community gardening program in Phoenix, Arizona. We interviewed community organizers and collected social survey data in low-income, inner-city neighborhoods. Current gardeners, ex-gardeners, and nongardeners were surveyed. To our knowledge, these groups have not been analyzed separately in other studies. We asked how perceptions of gardening differ between these groups and garden organizers, and what factors influence residents' participation in community gardens. We inquired if and how residents connect gardening with a larger vision for their neighborhood. Finally, we explored how food justice is experienced within the context of a poor, minority community.

\section{Benefits and Burdens of Community Gardens}

\section{Benefits}

Community gardens can play a major role in newly evolving urban agriculture systems that are designed to enhance community food security (Allen, 1999; McCullum, Desjardins, Kraak, \& Ladipo, 2005). Participants in urban community gardens are three and a half times more likely than nonparticipants to consume fruits and vegetables five times a day (Alaimo, Packnett, Miles \& Kruger, 2008). Benefits of gardening to individual participants have been documented in previous surveys. For example, Armstrong (2000) found that among the important reasons people gave for participating 
in a community garden were access to fresh foods, enjoyment of nature, and health benefits. Lee (2001) found that immigrant populations with previous agricultural experience used community gardens to connect with their homeland, and that they value beautification and growing traditional vegetables as aspects of community gardening.

Clayton (2007) found that gardens are commonly used to appreciate nature and to improve the environment. Community gardens increase public awareness of environmental stewardship and local control over the food system (Peters, Bills, Wilkins, \& Fick, 2008). They have been credited with reducing ambient air temperature in summer and aiding with rainfall runoff, noise control, food provisioning, attracting birds and pollinators, and providing points of recycling organic matter into the soil (Schmelzkopf, 1995). The Millennium Ecosystem Assessment defined these impacts as ecosystem services that benefit the environment (2005).

In the last three decades, academics and community organizers have come to see the social benefits of community gardens. They bring neighborhood residents together to form wider social networks and cultivate greater community involvement (Glover, Shinew, \& Parry, 2005). This increased involvement strengthens neighborhoods' ability to address issues of social justice and ways to increase cultural enrichment (Armstrong, 2000; Schmelzkopf, 1995). Local community food movements can forge networks among residents, nongovernmental organizations, and state agencies, and can begin severing dependency on industrialized global food (Wekerle, 2004). Although past surveys have shown how communities as a whole perceive gardening, differences in perception among gardeners, ex-gardeners and nongardeners within a community have not been studied. This is potentially important in investigating the reasons why community gardens fail.

\section{Burdens}

In a longitudinal national survey of more than 6,000 community gardens in the U.S., the total number of community gardens increased, but about $9 \%(n=542)$ of existing community gardens were lost over the duration of the four-year study (American Community Gardening Association, 1998). Some gardens are endangered due to external pressures, such as repurposing of the land by government and/or private industry (Irazábal \& Punja, 2009; Schmelzkopf, 2002). More often, gardens struggle with low levels of community participation or interest in the gardening initiative. Community gardens confront "gardener drop-out," when people sign up for a plot, decide the work is too difficult or the summers too hot, and then abandon the land (Surls, 2008). The primary reason for garden failure cited in the national survey of community gardens was abandonment (49.4\%), followed by loss of a garden to a public agency (19.7\%) (American Community Gardening Association, 1998). Ferris, Norman, and Sempik (2001) argued that successful community gardens must be designed around the social context of the neighborhood if the garden is to be accepted by the community. Gardens fail when foisted upon neighborhoods through top-down decisions (Schmelzkopf, 1995). Neighborhood resistance can hinder or eliminate the multiple benefits that a community garden might otherwise provide.

The gardens we discuss in this article are located in an area that has a history of unsuccessful community gardens, and garden organizers had informed us of declining participation in the remaining community gardens. When these gardens were initiated eight years ago, membership was between 10 and 15 residents per garden, but since then some gardens had dropped to one member and others were totally abandoned.

\section{Research and Action Partnership}

In September 2009 we began a partnership with residents and a nonprofit community development organization, the Phoenix Revitalization Corporation (PRC), in a roughly two-square-mile area in Phoenix, Arizona. This area comprised eight neighborhoods and was chosen for its low level of income, location in the Phoenix urban core, and the community organizer's stated intention of expanding the struggling community gardening program. The bounds of our study site were 
suggested by our partner nonprofit organization as it is the core area of that organization's engagement. The nonprofit describes its core area of engagement:

Sixty-six percent $(66 \%)$ of the public housing in the City of Phoenix is in [the eight neighborhoods]. There is nineteen percent $(19 \%)$ unemployment rate and fifty-two percent $(52 \%)$ of the population lives below the poverty level. (PRC, 2010, p. 7)

The most recent neighborhood-level census data available from 2000 shows the community had a population of over 10,000 people living in 3,200 dwellings. Seven percent of the housing stock was vacant, $66 \%$ renter-occupied, and $26 \%$ owneroccupied. The average median annual income across the eight neighborhoods was $\$ 14,500$, and the highest median income among the neighborhoods was $\$ 23,500$. The racial and ethnic composition was $76.2 \%$ Hispanic, $16.9 \%$ African-American, 4.2\% White (non-Hispanic) and 1\% Asian (U.S. Bureau of the Census, 2000). Sometime after the year 2000, an influx of retired Chinese immigrants moved into public housing in two of these neighborhoods, noticeably increasing the Asian population.

Indicators of food desertification within the study area are emerging through other research. The Reinvestment Fund (2010) identified three of the eight neighborhoods as Low Access Areas in a nationwide study of supermarket access. A study of the area based on the Nutritional Environment Measure Survey found that this entire community lacks fresh produce in neighborhood stores and has significantly less availability of healthy food options compared to unhealthy food options (Crouch, 2011; Crouch, Phoenix Revitalization Corporation, \& Harlan, 2011). At one time the study area had a farmers' market, but in 2005, a more profitable location opened downtown and the farmers moved.

\section{History of the Gardens}

Our nonprofit partner sponsors a community gardening program in the neighborhoods and provides funding and technical support. A new garden is initiated when a group of residents approaches the nonprofit with a request for garden space and supplies. The nonprofit then locates a suitable area and makes arrangements with the owner for use of the property. The nonprofit works with the city to cover hook-up to the water supply and monthly costs. The residents then form a gardening club with their own charter and organizational rules. The club is responsible for maintaining the garden, growing the produce, and deciding how the produce is distributed. The nonprofit organization describes the garden clubs as independent and autonomous units, with the exception of the funding and technical support the organization provides.

Until January 2010 a gardening coordinator met with each independent gardening club once a month. He provided seeds, equipment, and technical instruction. He also wrote a column for the nonprofit's quarterly newsletter, which was distributed to some 1,500 homes. The gardening coordinator is bilingual, speaking both English and Spanish. He has become fatigued, but he may return to coordinating the gardens in a couple years.

There are currently six small community gardens sponsored by our nonprofit partner. Of the six community gardens, only one continually uses all available plots. Two others comprise mostly unclaimed plots. Periodic visits to these gardens during one year showed only sporadic plantings within a few of the available plots. The fourth garden is located within a day school.

Two other gardens are totally abandoned and are now sometimes used by children at play. Organizers and community gardeners told us that repeated vandalism discourages use of the land. At the time of this writing, a fence has been proposed for the abandoned plots. A seventh garden is under construction, and recruitment for its gardening club membership is underway.

In cities hosting more established community gardening programs, the gardens in these Phoenix 
neighborhoods would probably be classified as "pocket gardens" (Ferris et al., 2001). The gardens are all less than 1,000 square feet and are composed of unedged, tilled soil. Compost, when it is available, is added to the soil. Some composting is done on site; most of the gardens rely on purchased soil amendments. All the gardens are watered from hoses connecting to locked spigots. Garden club members have keys in order to access the spigots. None of the community gardens has a sign alerting residents to the garden's existence or availability, although one of the gardens has a notrespassing sign on the fence.

Throughout our year of ethnographic observations we recorded which gardens were most actively used (table 1). The largest and most active community gardening club is composed of 12 people, most of whom speak only Mandarin Chinese. Their garden has slightly terraced raised beds so that water flows from the highest plots to the lowest. Tall plants, such as corn, are planted around the perimeter. The interior plots are devoted to tomatoes, peppers, and leafy greens. Due to lack of translators, communication between this garden club and the garden coordinator was limited to pointing at pictures and hand gestures. The second most active garden is maintained by a local Girl Scout troop. This garden has straight furrows, and the produce is given to a retirement community. The third garden is also associated with a retirement community and consists of five raised beds constructed with plywood and a ground-level tilled bed. The raised bed frames are crumbling, and over the last year we have not observed any new plantings. One community gardener sporadically works the tilled area. The remaining gardens were unused, but gardening club recruitment will begin after fencing is installed.

\section{Hypotheses}

Our nonprofit partner enlisted our help to explore whether there was potential to increase the recruitment and retention of local gardeners in order to sustain a more successful community gardening program. The small size of the community gardens and their lack of visible signage led us to hypothesize that the majority of neighborhood residents were not aware of the local community gardening program. We also hypothesized, based on the research findings of others, that residents of these neighborhoods would associate or anticipate some substantial benefits from community gardening, but that they would also associate and anticipate burdens with gardening, which could decrease their participation if left unaddressed. These perceptions may differ among people with different levels of gardening experience, and they may or may not align with the premises of the community gardening initiative promoted by the nonprofit.

\section{Research Methods}

Academic partnerships with community-based stakeholders can offer insights into complex social processes operating in the practice of urban agriculture (Austin, 2004; Feenstra, 2002). Guided by the interests of our community partners, we collected qualitative and quantitative data to study their gardening initiative. The ethnographic data (interviews with key informants and field obser-

Table 1: Community Gardens Within Neighborhoods, Listed in Descending Order of Use

\begin{tabular}{cllll}
\hline Garden & Members & Type & Population Served & Fencing \\
\hline 1 & 12 members & Tilled soil & Retirement community & Fenced community \\
\hline 2 & Girl Scouts & Tilled soil & Retirement community & Fenced \\
\hline 3 & 1 member & Raised beds & Retirement community & Fenced \\
\hline 4 & Not available & N/A & Day school & Fenced \\
\hline 5 & Unused & Tilled soil & All ages & Waiting for fencing \\
\hline 6 & Unused & Tilled soil & All ages & Waiting for fencing \\
\hline
\end{tabular}


vations) and survey responses of a much larger sample of residents offer a compelling new understanding of why community garden initiatives may struggle to find participants.

\section{Ethnographic Methods}

To familiarize ourselves with the community and its gardening program, we conducted interviews with seven community organizers. We attended monthly community meetings hosted by our nonprofit partners and the city of Phoenix to talk with residents. In October 2009 at a community fair we handed out seeds and talked with residents about their gardening experiences. During the summer months the first author helped construct a small community garden for an after-school program.

\section{Survey Methods}

After gathering knowledge about the local community gardens, we created a survey to explore neighborhood sentiment about the benefits and burdens associated with community gardening. We compiled lists from this existing literature (Armstrong, 2000; Clayton, 2007; Ferris, et al., 2001; Lee, 2001; Saldivar-Tanaka \& Krasny, 2004; Schmelzkopf, 1995; Voicu \& Been, 2008). Interviews with organizers and residents revealed other benefits and burdens that were not addressed in this literature. For example, some residents and community organizers expressed dismay at the difficulty of maintaining a garden during Phoenix summers. The average daily high temperature in summer is roughly $105^{\circ} \mathrm{F}$ (WRCC, n.d.), and Arizona leads the U.S. in heat-related deaths (CDC, 2005). Yet we knew many gardens in Phoenix are cultivated during the summer. We suspected that comparing groups with more and less gardening experience could add to our understanding of how to get people into gardening and keep them interested.

Twelve possible benefits of gardening and 13 possible burdens of community gardening were listed on the survey, as well as an option for respondents to write in other answers. Respondents were asked to choose three benefits and three burdens of gardening that were most important to them because this would help us to identify themes for building a community garden that residents would find most attractive. Respondents had to fill in at least one benefit (or burden) to be included in the analysis. Responses to other questions about gardens on the two-page survey are discussed in the Results section.

With assistance from the community nonprofit, we administered the survey in March 2010 from a booth at a communitywide fair in order to reach the widest audience. The survey was available in English, Spanish and Mandarin Chinese. Spanish and Mandarin Chinese translators were on hand to facilitate the completion of surveys by non-English speakers or readers. Free bags of fresh fruits and vegetables supplied by a local community supported agriculture (CSA) group, were given to residents who completed the survey. Our respondents were not a truly random sample of the population, and so our statistical results may be subject to sampling error. ${ }^{1}$ In situations such as ours, one can only capture as large a sample as possible, document the possible sources of bias, and use the nonrandom sample (Bernard, 2006, p. 187). To the extent possible, we triangulated our statistical findings with qualitative data.

\section{Results}

\section{Results from Interviews and Observations}

Despite many setbacks, most community organizers in both informal and semistructured interviews voiced their commitment to continuing the existing gardens and cultivating a neighborhood-wide community gardening initiative. Community organizers often conceptualized gardening as an activity for retired residents or children, and our observations confirmed that. Three of the existing gardens are associated with low-income retirement commu-

\footnotetext{
${ }^{1}$ Random sampling of the population via telephone or mailing would have increased the costs of the survey beyond our means. Community organizers suggested that linguistic barriers and neighborhood resistance to unsolicited calls or mail would result in low response rates. An Internet-based survey limits the population sample to those who have Internet access, which would likely result in a very small sample skewed toward a more educated population. Citing safety concerns, community organizers requested no door-to-door canvassing.
} 
nities, one is maintained by Girl Scouts, and other children-oriented community gardens are in the planning phase. Of all the gardens listed, only two (which are temporarily unused until fencing is installed) are available to nonretired adults. Yet in these types of neighborhoods, economically disadvantaged working-age adults may struggle to meet their nutritional needs, and women in particular are vulnerable to food insecurity (Townsend, Peerson, Love, Achterberg, \& Murphy, 2001). The active gardening clubs revealed that female community gardeners outnumbered male community gardeners four to one which may, in part, reflect a gendered struggle with food insecurity among neighborhood residents.

Regardless of all the problems and very low participation rates evident in the current community gardens, there were indications that residents wanted community gardens in their neighborhoods. We learned from interviews that in 2009 community organizers had engaged in round-table talks with neighborhood stakeholders - service providers, nonprofits, local government officials, and academics - and participating residents to create a Quality of Life Plan (QLP), a vision for the future of the community. The QLP is a:

...document to be used collectively by residents and stakeholders to work towards creating neighborhoods that are healthy, safe, economically vibrant, and happy places for families and individuals to live, work and play. (PRC, 2010, p. 6)

Stakeholders and the residents who participated in the QLP discussions identified community garden expansion as vital to providing opportunities for social interactions and education on healthy eating (PRC, 2010, p. 21). They would like a new farmers' market to partner with the community gardens, linking local food production with distribution and economic development (PRC, 2010, p. 35). To the extent that stakeholders and participating residents represented the broader community's sentiment toward the gardening program and new farmers' market, there appears to be some measure of "buy-in" to the local food initiative. One organizer expressed her desire to expand the gardening program, saying, "I would like to see a farmers' market over here. And a big garden, like a really big garden."

Community organizers offered multiple opportunities for residents' input to the QLP, but they faced many challenges to gathering opinions of a representative sample. To the extent possible, meetings were arranged around resident's schedules, but community organizers spoke of time and travel burdens for neighborhood residents who would otherwise attend community meetings. Uncertainty regarding what exactly the QLP is, and what it is intended to do, also may pose a hurdle to embracing it as a plan of action. One tentative resident said: "At first I was scared to participate in the $[\mathrm{QLP}]$ plan because I did not understand. Then I realized that my opinion was heard and I felt more comfortable" (PRC, 2010, p. 10). The difficulties in getting residents to engage in the process of drafting of the QLP challenges the otherwise inclusive nature of the document and the interpretation of how much resident support exists for community gardening.

\section{Results from Survey of Residents}

Our survey was completed by 149 community residents ages 18 and older. To better understand how well our sample represents the demographics of the neighborhoods, we compared the gender, ethnic and age profiles of our respondents with the demographic breakdown by census block group in the 2000 U.S. Census (table 2). ${ }^{2}$ Women were more likely than men to complete our survey, as were respondents over 40 years of age. We had the only booth with written materials and translators for Mandarin speakers, so the Chinese population was also more likely to complete our survey.

\footnotetext{
2 Preliminary 2010 census data pertaining to population ethnic composition in the neighborhoods has recently become available: $74.4 \%$ Hispanic; $13.8 \%$ Black or African American; 7.1\% White (non-Hispanic); 1.8\% Asian; 1.6\% American Indian; 0.1\% Other (U.S. Census Bureau, 2010). All calculations in table 2, however, are made using 2000 census data to avoid using data from multiple census years.
} 
The first question asked respondents "Are you interested in gardening?" Using a five-point response scale of interest in gardening with $5=$ very interested and $1=$ not interested, the mean level of interest was 4.4 for 94 respondents who answered that question, and $83 \%$ replied that they were very or somewhat interested (table 3). This response indicates a high level of residents' interest in gardening.

Of the 131 respondents who stated their current status with respect to gardening, $26 \%(n=34)$ identified themselves as current gardeners, 35\% $(\mathrm{n}=46)$ as ex-gardeners and $39 \%(\mathrm{n}=51)$ as nongardeners. Home gardeners, community gardeners, and nonagricultural gardeners were represented in the category of current gardener. Overall, one of four survey respondents in this sample was currently engaged in some type of gardening, and three of five respondents had gardening experience.

A working definition of a community garden was included in the survey: "A community garden is a single piece of land gardened by a group of people." Respondents were asked, "If you are interested in gardening, where would you prefer to garden?" Twenty-one percent $(\mathrm{n}=31)$ selected community gardens, $41 \%$ percent $(n=61)$ selected gardening at home, and $1 \%(\mathrm{n}=2)$ selected school gardens.

Table 4 shows the percentages of men and women, ethnicities, and ages interested in community gardening. In parenthesis we show the number of respondents interested in gardening divided by the total number of respondents in that gender, ethnic, or age category (e.g., $15.3 \%$ or six of 39 males who responded to the survey were interested in gardening). Although some of the percentages are based on small numbers of respondents, table 4 suggests which groups expressed the most interest in community gardening and which groups may need further encouragement. A greater proportion of women reported interest in community gardening than men. In this sample, African Americans and Whites seemed the most likely to be interested in community gardening. Hispanics and Asians

Table 3: Level of Interest in Gardening ( $N=94)$

\begin{tabular}{lc}
\hline Response & Gardening Interest \\
\hline Very interested & $59.6 \%(56)$ \\
\hline Somewhat interested & $23.4(22)$ \\
\hline Neutral & $13.8(13)$ \\
\hline Little interest & $2.1(2)$ \\
\hline Not interested & $1.0(1)$ \\
\hline Total & $100.0 \%(94)$ \\
\hline Mean level of interest & 4.4
\end{tabular}


Table 4: Percentage of Each Group That Indicated Interest in Community Gardening

\begin{tabular}{|c|c|c|c|}
\hline \multirow[b]{2}{*}{ Gender } & \multirow[t]{2}{*}{ Demographic } & \multicolumn{2}{|c|}{$\begin{array}{l}\text { (\# of respondents interested) / } \\
\text { (total \# of respondents in group) }\end{array}$} \\
\hline & & $15.3 \%$ & $(6 / 39)^{a}$ \\
\hline & Female & 27.1 & $(25 / 92)$ \\
\hline \multirow[t]{3}{*}{ Total } & & 23.7 & $(31 / 131)^{b}$ \\
\hline & American Indian & $0.0 \%$ & $(0 / 1)$ \\
\hline & Asian & 18.4 & $(7 / 38)$ \\
\hline \multirow[t]{4}{*}{ Ethnicity } & Black or African American & 34.2 & $(12 / 35)$ \\
\hline & Hispanic & 14.8 & $(8 / 54)$ \\
\hline & White/Caucasian & 33.3 & $(3 / 9)$ \\
\hline & Other & 25.0 & $(1 / 4)$ \\
\hline \multirow[t]{3}{*}{ Total } & & 22.0 & $(31 / 141)^{b}$ \\
\hline & Younger then 25 & $40.0 \%$ & $(4 / 10)$ \\
\hline & $25-34$ & 26.3 & $(5 / 19)$ \\
\hline \multirow[t]{4}{*}{ Age } & $35-44$ & 13.6 & $(3 / 22)$ \\
\hline & $45-54$ & 20.0 & $(3 / 15)$ \\
\hline & $55-64$ & 29.1 & $(7 / 24)$ \\
\hline & 65 or older & 20.4 & $(9 / 44)$ \\
\hline Total & & 23.1 & $(31 / 134)^{b}$ \\
\hline
\end{tabular}

a Number of respondents interested in gardening divided by the total number of respondents in the same gender, ethnic, or age category.

b Differences in total n's are accounted for by missing data on the gender, ethnicity, and age variables.

seemed to have lower levels of interest. Younger people seemed to be more interested than older people. Nevertheless, some people of all ages were interested in gardening. In sum, there was a substantial amount of interest in gardening, including community gardening, in this community.

A large majority of community residents did not know about the community gardens in their neighborhoods, and $72 \%(n=107)$ of the respondents did not know of the existing community gardens program. Of the respondents who indicated interest in working in a community garden, $67 \%$ $(n=22)$ did not know of a community garden near their home. The data support our first hypothesis that more residents are interested in community gardening then are aware of the program. Furthermore, $82 \%(n=112)$ of total respondents had not heard of the local food initiative outlined in QLP, and $77 \%(\mathrm{n}=24)$ of respondents interested in community gardening had not heard of the local food initiative.

\section{Benefits and Burdens of Gardening}

The perceived benefits of gardening for the categories of gardeners, ex-gardeners and nongardeners are shown in figure 1 , reported in descending order of the percentage of respondents who indicated the item as a benefit. Analysis of variance was used to test for significant differences in perceptions among the three categories. Overall, residents' perceptions of the benefits of gardening revolved strongly around nutritious food (61\%), exercise $(49 \%)$, and extra food $(49 \%)$. Other gardening benefits important to many were helping the environment $(45 \%)$ and relaxation (37\%). Gardeners, significantly more than others, admired the beauty of gardens (pretty to look at, $\mathrm{F}$ $=3.071, \mathrm{p}=0.05)$. Gardeners were also more likely to appreciate the cooling effects of plants, although the difference was not statistically significant. Exgardeners were significantly more likely to perceive that they had given up an important sense of accomplishment $(\mathrm{F}=2.874, \mathrm{p}=0.06)$. Earning extra income (from selling produce) (16\%), socializing with people (11\%), and increasing land values $(10 \%)$ were not rated highly important by any group.

The perceived burdens of gardening are reported in descending order of the percentage of respondents who indicated the item as a burden, as shown 
Figure 1. Percent of Respondents by Gardening Status Who Identified the Item as an Important Benefit of Gardening ( $N=131)$

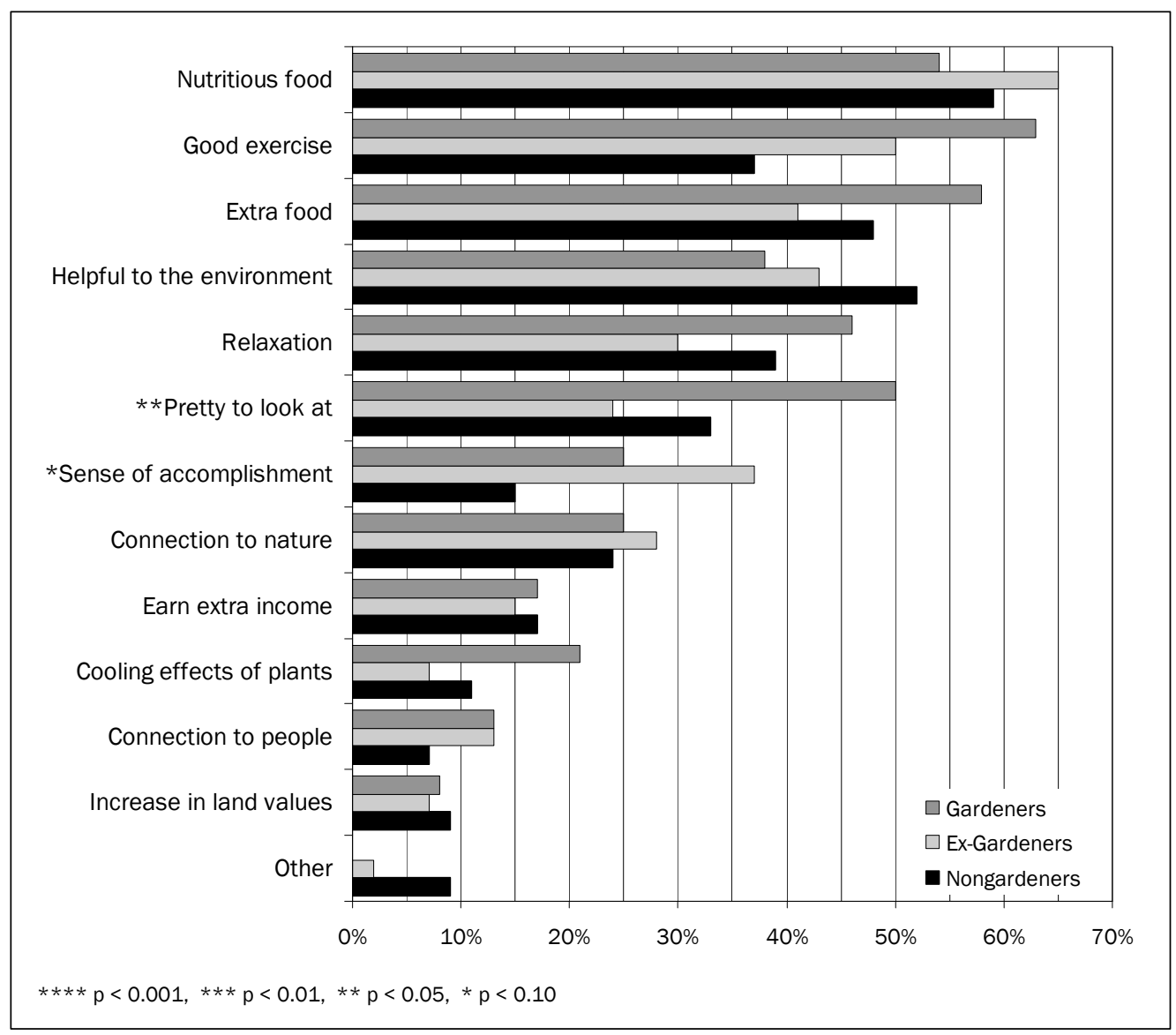

listed hard work

$(10 \%)$, messy gardens $(7 \%)$, getting dirty $(6 \%)$, or feeling unsafe $(5 \%)$ as barriers to participation in gardening. No respondents indicated that they thought gardening is not enjoyable.

For each benefit and burden item, we calculated the differences in percentages between respondents who said they were interested in gardening at home and those who said they were interested in community gardening. None of the ttests showed a in figure 2 (next page). Overall, lack of space (48\%) and excessive heat $(39 \%)$ were the two largest barriers to gardening for both gardeners and exgardeners. The ex-gardeners were significantly more likely to say that being too hot was a burden (too hot, $F=5.187, p=0.01$ ). Gardeners were significantly more likely to mention crop loss as a burden (crop loss, $\mathrm{F}=3.706, \mathrm{p}=0.03$ ), which is potentially related to hot weather. Two burdens that were significantly more important for nongardeners were not knowing how to garden (do not know how, $F=7.837, p=0.001)$ and the belief that gardening would take too much time (takes too much time, $\mathrm{F}=2.5, \mathrm{p}=0.09$ ). Interestingly, nongardeners did not mention as often as the other groups that excessive heat would be a barrier to gardening. Although some respondents acknowledged that gardening was harder than grocery shopping (14\%), very few statistically significant difference between how these groups perceived gardening.

In sum, our second hypothesis was supported: residents sampled in this low-income community perceived some important benefits to gardening, which mainly entail access to good food. They also perceived barriers that make gardening difficult, notably lack of space to garden and excessive heat. Those without gardening experience felt hampered by a lack of knowledge.

\section{Discussion}

This study is the product of an active and ongoing partnership among academics, community organizers, community stakeholders, and the residents of eight low-income and minority neighborhoods. The data we collected are being utilized to further engage the neighborhoods and 
Figure 2. Percent of Respondents by Gardening Status Who Identified the Item as an Important Burden of Gardening $(\mathrm{N}=108)$

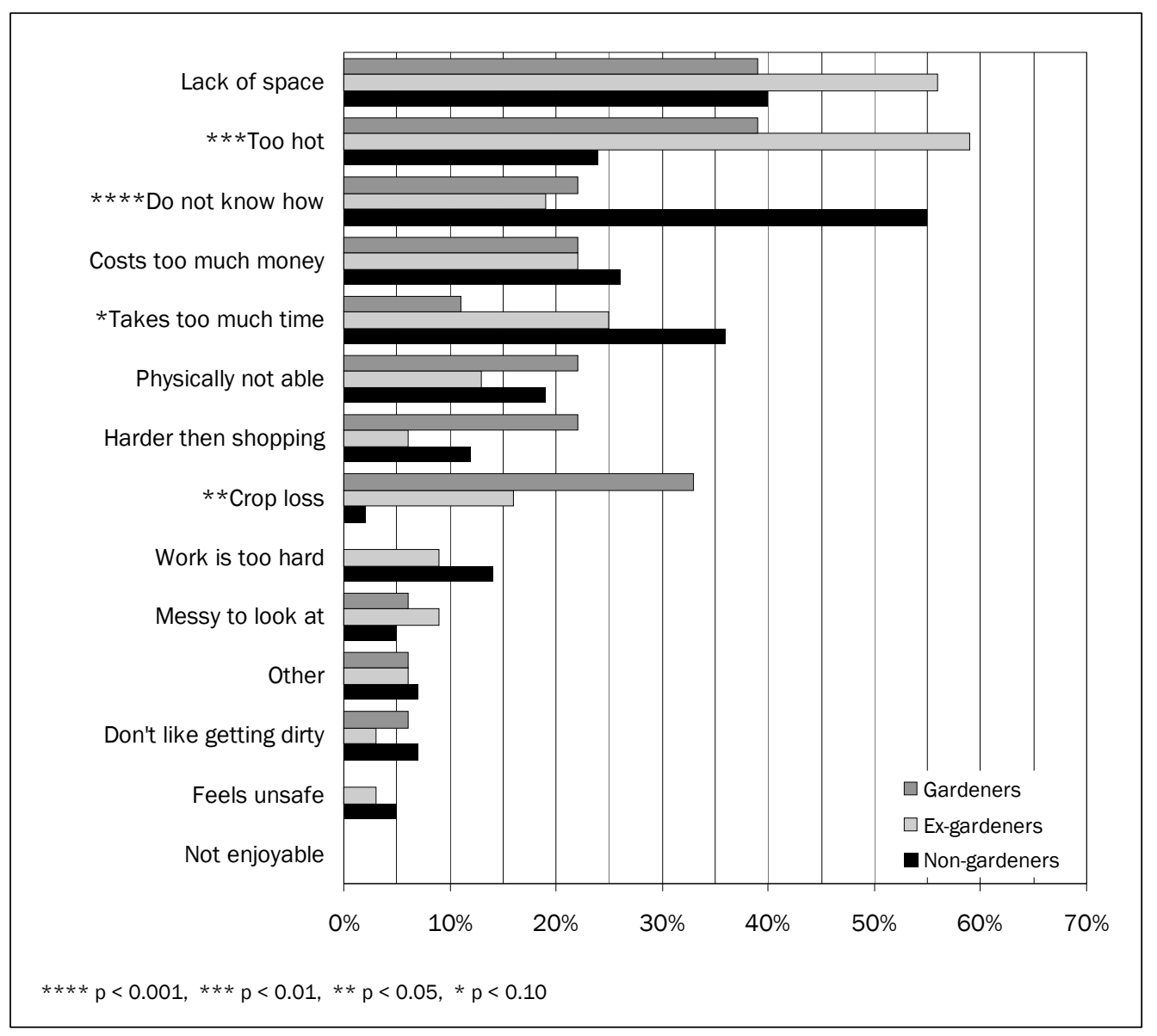

in community gardening. This section discusses strategies that may increase resident interest in joining the community gardening and local food initiatives.

To increase understanding of complex on-theground issues facing this local food initiative, we must examine the multiplicity of perspectives surrounding the project. We compared the gardening objectives stated in the QLP with our ethnographic and social survey findings. We help strengthen their community gardening program and local food initiative, as called for in the Quality of Life Plan. The QLP is very much a living document. We are working with community organizers to provide substantive contributions to later drafts of the QLP based on our findings.

Our survey showed that only $28 \%$ of the respondents knew of the existing community-garden program and $21 \%$ of respondents indicated an interest in community gardening. The number of respondents who indicated they were interested in community gardening exceeded the existing number of community gardeners. Simply cultivating awareness of the garden program may substantially increase current garden membership. However, barriers still exist and a substantial portion of the population did not indicate interest found several statistically significant differences in perception among groups with and without gardening experience, indicating that residents cannot be treated as a homogenous group when designing a community garden or local food initiative. Multiple perceptions of community gardening exist in the same neighborhoods between residents as well as between residents and the staff and volunteers with the local food initiative. This is not a simple case of "if you build it, they will come." Meeting the needs and desires of so many disparate groups will require careful planning and action.

The objectives of the QLP community gardening initiative are to generate supplemental income and provide greater opportunities for residents to socialize. Less than $20 \%$ of residents, however, 
currently associate gardening with either of those objectives. This discrepancy may have contributed to the difficulty community organizers and stakeholders had with sustained resident participation in drafting the community gardening section of the QLP. The survey allowed us to take a larger sample of neighborhood gardening sentiment than was easily available to stakeholders and community organizers.

The QLP calls for community gardens to supplement income. Successful market gardens and community supported agriculture programs can be found in Phoenix, but in the community we studied residents did not strongly associate gardening with an extra source of income. Armstrong (2000) had similar findings in upstate New York: Community gardeners were more interested in health benefits associated with gardening than in using the garden as a way to supplement their income. The recent loss of their farmers' market may have further impacted the neighborhoods' negative perceptions of supplementing income through gardening.

The QLP states that community gardens should be used as a place for residents to socialize. Yet we found no statistically significant differences in perceptions of burdens and benefits between residents interested in gardening at home and those interested in community gardening. Therefore, we believe residents placed home gardening and community gardening under the same umbrella. So it may come as little surprise that respondents who indicated an interest in community gardening did not associate the garden with a place to socialize. Educating potential community gardeners about sharing seeds, produce, and gardening tips may demonstrate some advantages of gardening in company. Placing a bulletin board in the community garden could serve to increase awareness of the social aspects of community gardening. Large colorful signs advertising the existence of the garden and how to gain access to it could increase both the social awareness of the garden and the likelihood that it will be viewed as a place of social interaction. To meet QLP goals, further promotion of opportunities for market gardening and socializing in the gardens will be necessary. Scheduling fun gardening activities such as garden parties, harvest parties for children, and opening the gardens for social events may increase awareness, interest, and participation.

Neighborhood residents envisioned a community garden that provides plentiful and nutritious food, exercise, beautification, and a sense of accomplishment. The perceived burdens for residents included lack of garden space, little knowledge of gardening, substantial time commitments, and hot summers. Since the residents represent the pool of potential community gardeners, understanding their perceptions will be critical in creating a garden that welcomes their participation rather than a garden that goes unnoticed and underappreciated. An inclusive garden design must acknowledge neighborhood food desertification, reflect critical thinking about justice issues, and construct an environment in which residents would like to relax, socialize and garden.

Crouch et al.'s ongoing food-resource mapping project shows that this community fits the definition of a food desert: having low access to quality food (2011). It is not surprising then that residents' interest in gardening revolved most strongly around having extra food and nutritious food. The survey findings may reflect residents' difficulty in obtaining and affording fresh fruit and vegetables. Female-headed minority households are more likely to suffer food insecurity then male-headed minority households (Martin \& Ferris, 2007). In our study, $27 \%$ of women indicated an interest in working in a community garden compared with $15 \%$ of men.

The proportion of female participants in community gardens seems to vary by the design of the community garden. Schmelzkopf (1995) found more men participated in New York City community gardens that featured a clubhouse, but more women participated in family-oriented community gardens. Providing family-oriented community gardens with playground equipment could encourage mothers to come to the gardens with their children. If expectant mothers or children will be spending time in and/or eating 
food from a community garden, it should be tested for levels of lead in the soil and that may be taken up by the plants.

For many residents, a community garden may offer a chance to inexpensively attain high quality produce. In this context, a community garden can offer the physical space residents need to practice food justice. Low homeownership rates, apartment complexes, and public housing in the community we studied could be among the reasons for the greatest perceived burden: lack of space to garden. Inclusion of as many diverse groups as possible in a community garden program may help particularly vulnerable populations. Utilizing raised beds opens up the gardens to handicapped individuals. Locating translators to facilitate communication with non-English speakers invites an otherwise alienated group into the garden. High-yield, intensive gardening methods could be particularly attractive for residents struggling with food security.

The community garden can become a social space where agricultural and environmental knowledge is transferred from garden coordinators to residents and from one resident to another. A substantial burden for residents in our study area was "crop loss," which may reflect a lack of knowledge about gardening. Participation in a community garden could generate a reservoir of local agricultural knowledge and strategies to create a more just and equitable distribution of nutritious foods along with environmental benefits.

Respondents who were actively gardening were no more likely than nongardeners or ex-gardeners to select "helpful to the environment" or "connection to nature" as benefits. This supports Clayton (2007), who found that gardens were not generally perceived as part of a larger ecosystem, but instead were appreciated for specific nature-related benefits provided to the gardener. In our survey, nongardeners most strongly associated gardening with general environmental benefits, but it seems that association was not sufficient to encourage them to garden.
Gardeners, more then other populations, noted specific environmental benefits that impacted them directly, such as beautification and the cooling effects of plants. Instead of concentrating on broad environmental concerns, local food initiatives in poor and minority communities may gain more support if they construct a specific environment in which residents want to live, work and play. Alkon (2008) stated that, "by defining the environment as places where low-income people and people of color are, rather then where they are not, ecological issues are clearly connected to issues of inequity" [emphasis in original]. Designing a community garden that incorporates a heat-mitigation strategy might entice ex-gardeners back into neighborhood gardens. In the neighborhoods we studied, the most successful community garden is also the only garden with a shade sail.

Increasing local knowledge about community garden programs and the environmental benefits of gardens will be paramount to creating a sustainable local food initiative. Community fairs may provide an excellent place to reach out to local residents. Staffed with seven assistants, our survey booth was very busy for the duration of the three-hour fair. Many of our survey respondents wished to engage in conversations about gardening and find out more about the existing community gardening program and any plans for expansion. This may offer a hint as to how to promote community gardening programs and local food initiatives. Participation in local events such as a community fair increases communication between garden coordinators and potential community gardeners, which appears to be a major hurdle for struggling community garden programs.

\section{Limitations of the Study}

As a "research frame," community fairs attract a segment of the population that has both the time and interest to participate. The retired Asian community (composing the majority of currently active community gardeners) lives close to the location of

\footnotetext{
${ }^{3}$ A shade sail is an awning made from fabric or plastic that reduces the intensity of sunlight reaching the people or plants below.
} 
the community fair where we conducted our survey. Their retirement communities also provided transportation to the fair. These respondents were particularly interested in the gift bag of fresh fruit and vegetables and in talking about gardening. Removing or limiting retired Asian respondents from the survey sample would yield a sample demographic that more closely corresponds to neighborhood census data, specifically with regard to ethnicity and age of respondents. However, a sample that more closely represented the neighborhoods demographics would not have been representative of the Asians' active engagement in the existing neighborhood community gardens.

Women were also oversampled. However, they are generally the first to suffer the effects of food insecurity and also make up the majority of active community gardeners in our study area. Although the sample of survey respondents was not random, we learned that there are considerably more gardeners and ex-gardeners in the community than we expected.

\section{Conclusion}

Our findings provide valuable insight for community garden organizers in the southwestern U.S. and perhaps in other hot and arid regions. In a lowincome Phoenix community we found that access to nutritious food, extra food, and exercise were the top benefits that gardening provided to residents. Nongardeners connected gardening with helping the wider environment, but it was not sufficient inducement for them to start gardening. Gardeners were more likely to value personal environmental benefits, such as beauty and cooling. On the other hand, ex-gardeners left gardening because of a lack of space and intense summer heat. Lack of knowledge about gardening and time for gardening were major burdens for nongardeners.

The objectives of the gardening initiative were to generate supplemental income and provide greater opportunities for residents to socialize. Less than $20 \%$ of residents, however, currently connect gardening with either of those objectives. Multiple perceptions about community gardening exist in the same neighborhood. Programs need to align themselves with residents' perceptions. Education about community gardens may also align residents' perceptions with the local food initiative.

\section{Acknowledgements}

This project began in the Arizona State University Environmental Social Sciences 591 graduate seminar, Environmental Justice in the City. It is generously supported in part by NSF Grant No. DEB-0423704, Central Arizona-Phoenix LongTerm Ecological Research, and in part by NSF Grant No. GEO-0816168, Urban Vulnerability to Climate Change. The views expressed here do not necessarily represent those of the National Science Foundation. Special thanks to the staff of Phoenix Revitalization Corporation for their enthusiastic and active engagement in this partnership. We would like to thank Fengqiau Lu, Songling Du, Lucy Feng, Xiaoli Dong, Chrissie Bausch, Hannah Reitzel Rivera, and Gustavo Marco Antonio Ugarte Irizarri for their assistance with translating. We would like to thank Alicia Woodbury, Allain Barnett, David Miles, Katelyn Parady, Chrissie Bausch, and Richey Uranga for their help gathering survey responses. We would also like to thank Patty Black for her editorial work on this paper.

\section{References}

Alaimo, K., Packnett, E., Miles, R., \& Kruger, D. J. (2008). Fruit and vegetable intake among urban community gardeners. Journal of Nutritional Education and Behavior, 40(2), 94-101. doi:10.1016/i.jneb.2006.12.003

Algert, J. S., Agrawal, A., \& Lewis, S. D. (2006). Disparities in access to fresh produce in lowincome neighborhoods in Los Angeles. American Journal of Preventative Medicine, 30, 365-370. doi:10.1016/j.amepre.2006.01.009

Alkon, A. H. (2008). Paradise or pavement: the social constructions of the environment in two urban farmers' markets and their implication for environmental justice and sustainability. Local Environment, 13, 271-289. doi: $10.1080 / 13549830701669039$

Alkon, A. H., \& Norgaard, K. M. (2009). Breaking the food chains: An investigation of food justice activism. Sociological Inquiry, 79, 289-305. doi:10.1111/j.1475-682X.2009.00291.x

Allen, P. (1999). Reweaving the food security safety net: Mediating entitlement and entrepreneurship. 
Agriculture and Human Values, 16, 117-129. doi:10.1023/A:1007593210496

Alwitt, L. F., \& Donley, T. D. (1997). Retail stores in poor urban neighborhoods. The Journal of Consumer Affairs, 31, 139-163. doi:10.1111/j.1745-6606.1997.tb00830.x

American Community Gardening Association. (1998). National Community Garden Survey. Philadelphia, PA: Education Committee of the American Community Gardening Association.

Armstrong, D. (2000). A survey of community gardens in upstate New York: Implications for health and community development. Health and Place, 6, 319-327. doi:10.1016/S1353-8292(00)00013-7

Austin, D. E. (2004). Partnerships, not projects! Improving the environment through collaborative research and action. Human Organization, 63, 419428.

Baker, E. A., Schootman, M., \& Barnidge, E. (2006). The role of race and poverty in access to foods that enable individuals to adhere to dietary guidelines. Preventative Chronic Disease, 3(3). Available from http://www.cdc.gov/pcd/issues/2006/jul/ 05 0217.htm

Bernard, H. R. (2006). Research Methods in Anthropology: Qualitative and Quantitative Approaches (4 ${ }^{\text {th }} \mathrm{ed}$.). Lanham, MD: Altamira Press.

Block, D., \& Kouba, J. (2006). A comparison of the availability and affordability of a market basket in two communities in the Chicago area. Public Health Nutrition, 9, 837-845. doi:10.1017/PHN2005924

Centers for Disease Control and Prevention (CDC). (2005). Heat-related mortality: Arizona and the United States. Centers for Disease Control and Prevention, retrieved from http://www.cdc.gov/mmwr/preview/ mmwrhtml $/ \mathrm{mm} 5425 \mathrm{a} 2 . \mathrm{htm}$

Clayton, S. (2007). Domesticated nature: Motivations for gardening and perceptions of environmental impact. Journal of Environmental Psychology, 27, 215224. doi:10.1016/j.jenvp.2007.06.001

Crouch, C. (2011). Community food resource assessment in Central City South, Phoenix: A case study of community capacity building (Unpublished master's thesis). Arizona State University, Tempe, AZ.

Crouch, C., Phoenix Revitalization Corporation, \& Harlan, S. (2011, January). Community food resource mapping in Central City South, Phoenix: An exploratory study of community capacity building. Poster session presentation at CAP LTER Urban Ecology and Sustainability Symposium, Arizona State University, Tempe, Arizona.
Available online at http://caplter.asu.edu/ publications/cap-lter-symposia/thirteenth-annualposter-symposium-and-all-scientist-meeting/

Feenstra, G. (2002). Creating space for sustainable food systems: Lessons from the field. Agriculture and Human Values, 19, 99-106. doi:10.1023/A:1016095421310

Ferris, J., Norman, C., \& Sempik, J. (2001). People, land, and sustainability: Community gardens and the social dimension of sustainable development. Social Policy \& Administration, 35, 559-568.

Glover, T. D., Shinew, K. J., \& Parry, D. C. (2005). Association, sociability, and civic culture: The democratic effect of community gardening. Leisure Sciences, 27(1), 75-92. doi: $10.1080 / 01490400590886060$

Golan, E., Stewart, H., Kuchler, F., \& Dong, D. (2008). Can low-income Americans afford a healthy diet? Amber Waves, 6(5), 26-33.

Gottlieb, R., \& Fisher, A. (1996). Community food security and environmental justice: Searching for a common discourse. Agriculture and Human Values, 13(3), 23-32. doi:10.1007/BF01538224

Irazábal, C., \& Punja, A. (2009). Cultivating just planning and legal institutions: A critical assessment of the south central farm struggle in Los Angeles. Journal of Urban Affairs, 31(1), 1-23.

Larson, I. N., Story, T. M., \& Nelson, C. M. (2009). Neighborhood environments: Disparities in access to healthy foods in the U.S. American Journal of Preventive Medicine, 36(1), 74-81. doi:10.1016/j.amepre.2008.09.025

Lee, H. S. (2001). Community gardening benefits as perceived among American-born and immigrant gardeners in San Jose, California (Unpublished manuscript). Retrieved from College of Natural Resources, University of California, Berkeley, website: http://nature.berkeley.edu

Levkoe, C. Z. (2006). Learning democracy through food justice movements. Agriculture and Human Values, 23, 89-98. doi:10.1007/s10460-005-5871-5

Martin, K. S., \& Ferris, A. M. (2007). Food insecurity and gender are risk factors for obesity. Journal of Nutrition Education and Behavior, 39(1), 31-36. doi:10.1016/j.jneb.2006.08.021

McCullum, C., Desjardins, E., Kraak, V. I., Ladipo, P., \& Costello, H. (2005). Evidence-based strategies to build community food security. Journal of the American Dietetic Association, 105, 278-283. doi:10.1016/j.jada.2004.12.015 
Millennium Ecosystem Assessment. (2005). Ecosystems and human well-being: Synthesis. Washington, DC: Island Press.

Morland, K., Wing, S., \& Diez Roux, A. (2002). Neighborhood characteristics associated with the location of food stores and food service places. American Journal of Preventative Medicine, 22, 23-29. doi:10.1016/S0749-3797(01)00403-2

Pearce, J., Blakely, T., Witten, K., \& Bartie, P. (2007). Neighborhood depravation and access to fast-food retailing: A national study. American Journal of Preventive Medicine, 32, 375-382. doi:10.1016/j.amepre.2007.01.009

Peters, C. J., Bills, N. L., Wilkins, J. L., \& Fick, G. W. (2008). Foodshed analysis and its relevance to sustainability. Renewable Agriculture and Food Systems, 24(1), 1-7.

Phoenix Revitalization Corporation (PRC). (2010). Our community, our vision, our quality of life plan: Central City South Phoenix, Arizona. Phoenix Revitalization Corporation. Retrieved from PRC website: http://phxrevitalization.org/quailtyoflifeplan/ CCS Quality of \%20Life Plan 2010.pdf

Reinvestment Fund, The. (2010). Estimating supermarket access: Summary of TRF's research and analysis. Philadelphia, PA. Available online at The Reinvestment Fund website: www.trfund.com/ financing/realestate/EstimatingSupermarket Access-1pg.pdf

Saldivar-Tanaka, L., \& Krasny, M. E. (2004). Culturing community development, neighborhood open space, and civic agriculture: The case of Latino community gardens in New York City. Agriculture and Human V alues, 21, 399-412. doi:10.1023/B:AHUM.0000047207.57128.a5

Schmelzkopf, K. (1995). Urban community gardens as contested space. Geographical Review, 85, 364-381. $\underline{\text { doi: } 10.2307 / 215279}$
Schmelzkopf, K. (2002). Incommensurablity, land use, and the right to space: Community gardens in New York City. Urban Geography, 23, 323-343. doi:10.2747/0272-3638.23.4.323

Surls, R. (2008). Community garden start-up guide. Updated by Savio, Y., University of California Cooperative Extension, Los Angeles County. Retrieved from Los Angeles County Cooperative Extension website: http://celosangeles.ucdavis.edu/ Common Ground Garden Program/ Community Gardens.htm

Townsend, M. S., Peerson, J., Love, B., Achterberg, C., \& Murphy, S. P. (2001). Food insecurity is positively related to overweight in women. Journal of Nutrition, 131, 1738-1745.

U.S. Bureau of the Census. (2001). 2000 Census Block Groups: 1142002, 1143021-2, 1144022, 1147022 , 1148001-2, 1149002-3. Washington, DC: Self.

U.S. Bureau of the Census. (2011). 2010 Census Block Groups: 1173002, 1149002, 1148002, 1148001, 1144022, 1143021, 1142001. Washington, DC: Self.

U.S. Department of Agriculture (USDA). (2009, June). Access to affordable and nutritious food: Measuring and understanding food deserts and their consequences. Report to Congress. Washington, DC: Self.

Voicu, I., \& Been, V. (2008). The effect of community gardens on neighboring property values. Real Estate Economics, 36, 241-283. doi:10.1111/j.1540-6229.2008.00213.x

Wekerle, G. R. (2004). Food justice movements: Policy, planning and networks. Journal of Planning Education and Research, 23, 378-386. doi:10.1177/0739456X04264886

Western Regional Climate Center (WRCC). (n.d.). Phoenix, Arizona: Normals, means, and extremes. Retrieved from WRCC website: http://www.wrcc.dri.edu/cgi-bin/clilcd.pl?az23183 